\title{
Community Based Solar PV Distribution Model in Eastern Kenya: Success Factors and Challenges
}

\begin{abstract}
Benard O. Muok ${ }^{1}$
${ }^{1}$ Centre for Research, Innovation and Technology , Jaramogi Oginga Odinga University of Science and Technology (JOOUST)

Abstract: Access to clean ad reliable energy remains a fundamental bottleneck to the achievement of sustainable development goals in sub-Sahara Africa. In the past few years, solar energy has emerged as one of the most viable options to enhance energy access, especially in the rural areas where grid extension may not be economically feasible. This realisation has seen many governments and development partners focusing attention of promotion of solar energy. Kenya is recorded as country with one of the fasted growing solar market among the developing countries. Despite this achievement, there are a number of challenges facing solar market in Kenya. One of such challenges include identification appropriate distribution/business model. Different development agents employ different distribution models. One such model is the central charging centres. These centres operate on a rental system where portable solar lanterns are rented to household at a fee and the households have to drop and pick the lanterns either on daily basis or whenever the battery is discharged. Such centres was established at Ikisaya market in Kitui County by University of Oslo in collaboration with the Energy Resource Institute (TERI), African Centre for Technology Studies and other local partners. There years after the establishment, a study was carried out to determine the level of adoption of solar technology and identify the success factors and challenges. The study revealed that the centre has played a big role in introducing solar technology to a community who has predominantly been using kerosene candles. The main success factors were identified as the cost of technology, which was perceived to be lower than the alternative, ease of operation and ease of access of the technology. On the flip side governance issues remain a challenge to long tern sustainability.
\end{abstract}

\section{Introduction}

Sub-Sahara Africa remains the region with the highest energy poverty in the world making the region to miss modern energy services, which are crucial to human well-being and economic development. Although investment in modern energy supply (pre-dominantly electricity) is on the rise in the region, these gains are outpaced by the population growth. To date more than 620 million people in Africa still live without access to electricity and nearly 730 million people use hazardous, inefficient forms of cooking with severe impact on health as well as being a major contributor to environmental degradation. [1]

In Kenya, biomass energy consumption constitutes 68 per cent of the primary energy consumption while over 90 per cent of the rural household use firewood for cooking while lighting in rural areas is predominantly using kerosene candles. A recently report estimates 6.1 million (or 69.5 per cent) of all Kenyan households use paraffin as their main source of lighting [2]. Use of traditional biomass and kerosene expose the users to health risks from household air pollution and fire hazards. The traditional biomass system is also linked to deforestation and land degradation.

Rural electrification using solar PV has emerged as a viable option for the developing countries. PV systems not only provide reliable, clean, and environment-friendly energy but also create employment opportunities in the vicinity of its operation [3]. Kenya has abundant solar energy resources. Its daily average solar insolation is estimated to be about 4-6 kilowatt hours per square meter, which is considered one of the best for solar electric energy production in sub-Saharan Africa [4]. Off-grid and mini-grid solutions to energy access are therefore an important supplement to the electricity network expansion in the general sustainable energy electrification strategy of developing countries. Furthermore, solar market development has also been aided by the global fall in the solar PV prices over the last decade.

Despite the advantages that increased use of renewable resources such as solar could potentially

This article is published under the terms of the Creative Commons Attribution License 4.0 Author(s) retain the copyright of this article. Publication rights with Alkhaer Publications.

Published at: http://www.ijsciences.com/pub/issue/2018-11/

DOI: 10.18483/ijSci.1826; Online ISSN: 2305-3925; Print ISSN: 2410-4477 
bring to the country in terms of energy access to spur rural development, the uptake continues to be low due to barriers such as technological, economic, financial, market, public acceptance, infrastructural as well as legal and administrative barriers. The Kenyan solar market is rated as one of the fastest growing in Eastern Africa, and indeed in Africa. It is estimated that the overall solar market has increased by more than 100 per cent in Kenya with an estimated 300,000 solar home systems (SHS) installed and generating about 8-10MWp [5].

The current global recognition of access to energy being pivotal in achieving sustainable development goals (SDGs) and the United Nations Sustainable Energy for All (SEforAll) has seen many players enter the solar market including the civil society, government and other development agents. Due to this increasing interest and expansion of solar market in Kenya, different players are employing a different of distribution models. The advent of ICT driven innovation in marketing has further given more options especially for the poor who cannot afford the cost of technology by given them options of instalment payment or pay-as-you-go (PAYG).

It is against this background that University of Oslo in collaboration with the Energy Resource Institute (TERI), African Centre for Technology Studies and other local partners implemented the Solar Transitions project in Ikisaya village in Kitui County, Eastern Kenya. The aim of the project was to contribute to the knowledge on how to implement and use solar energy in developing countries in ways that are viable and contribute to social and economic development in local communities. The project established a community energy centre where portable solar lanterns are charged and rented to the surrounded communities. The centre also carries out computer services such as typing, printing and photocopying and a social hall with a connection to channel television network.

There years after the establishment, a study was carried out to determine the level of adoption of solar technology and identify the success factors and challenges. This is the result of a survey conducted in 2015.

\section{Methodology}

The study employed a mixed methodology to collect both primary and secondary data. Primary data was collected using pre-designed questionnaires, which was used for household interviews. Key informant interviews were conducted using guiding questions designed to capture key issues of the study. The study was conducted in Ikisaya Village in Kitui County, Eastern Kenya. A total of 60 households (37 per cent and 63 per cent female respondents, respectively) were interviewed and 10 key informants interviews including community leaders, project officers and local solar product dealers. The study also employed focused group discussion whose focus was to address centre management and governance issues. The key challenged faced in the study included low level of literacy a, poor road which made it access to household difficult.

\section{Results}

Demographic information

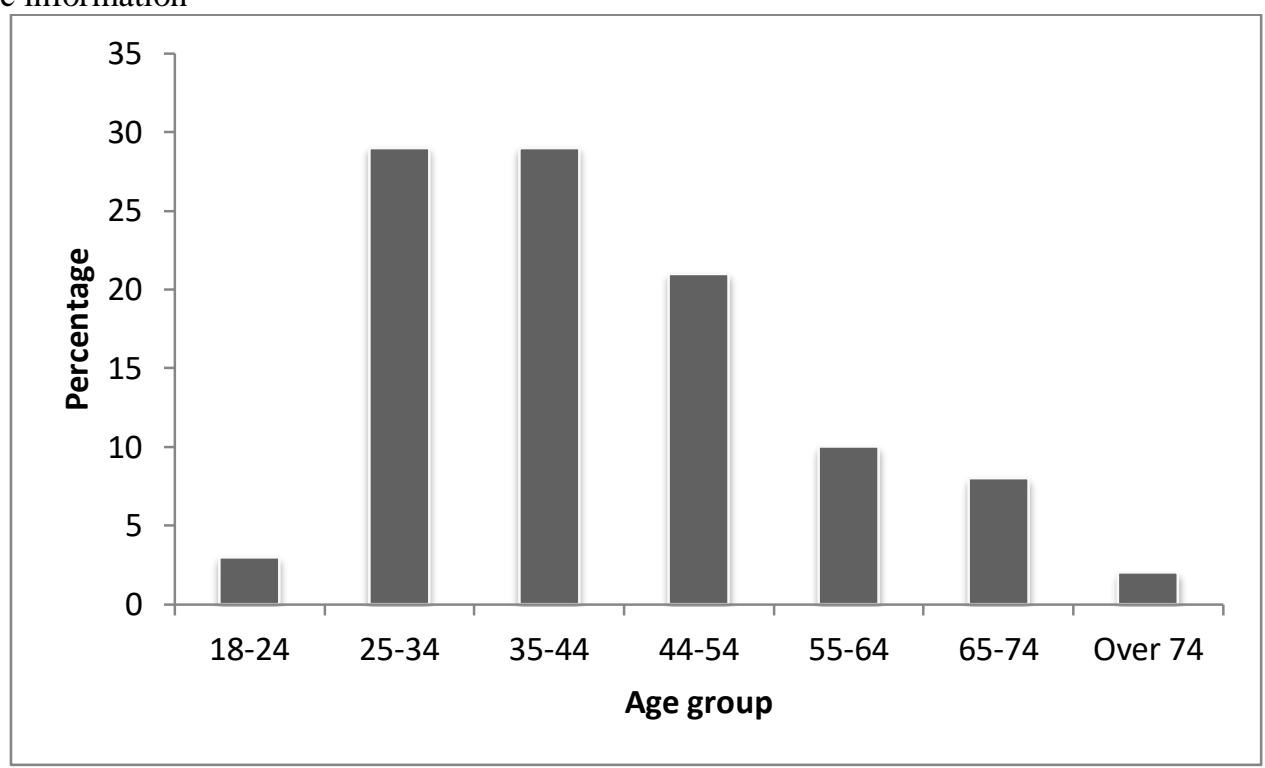

Fig 1 Age group of the respondents 
The population interviewed falls within a normal distribution range with a slight skew to the left and a meridian between 35-44 years (Fig 1).

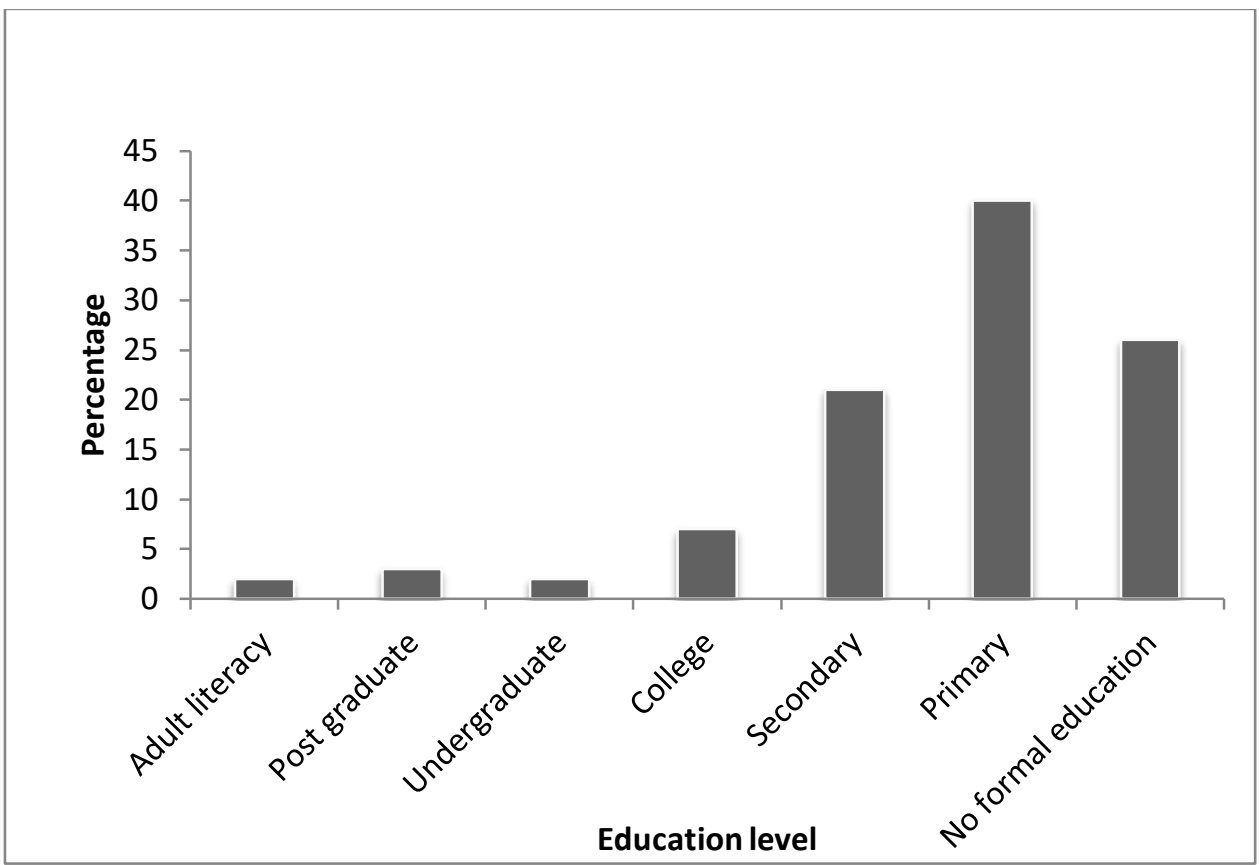

Fig. 2 Education level

The population has very low literacy level with close to 70 per cent of the population either having no formal education, attended adult literacy or primary (elementary) education (Fig. 2).

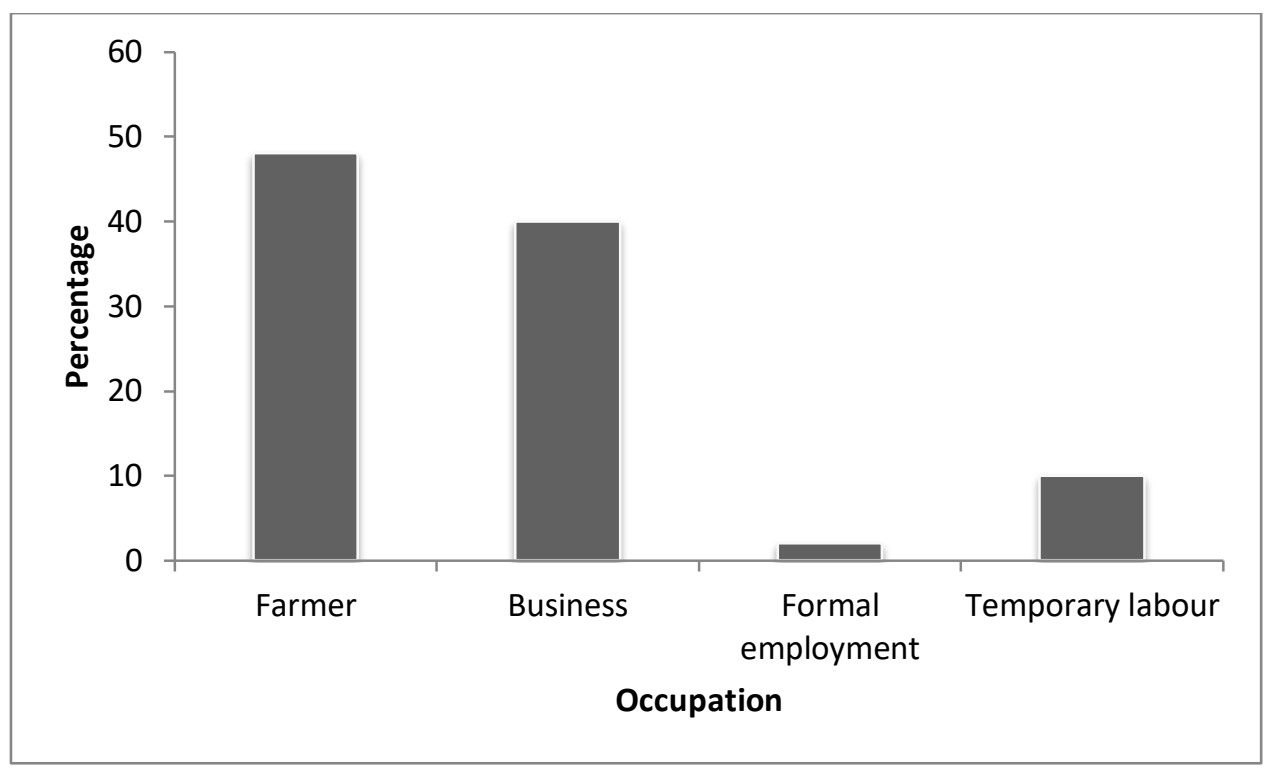

Fig. 3 Respondent's occupation

Majority of the population are either involved in farming or small business (Fig. 3). Those who are in formal employment are very low at about 2 per cent of the population.

98 per cent of respondents have access to solar. Of those who have access to solar 71 per cent have rented lanterns with only 23 per cent who own solar systems (Fig. 4). 


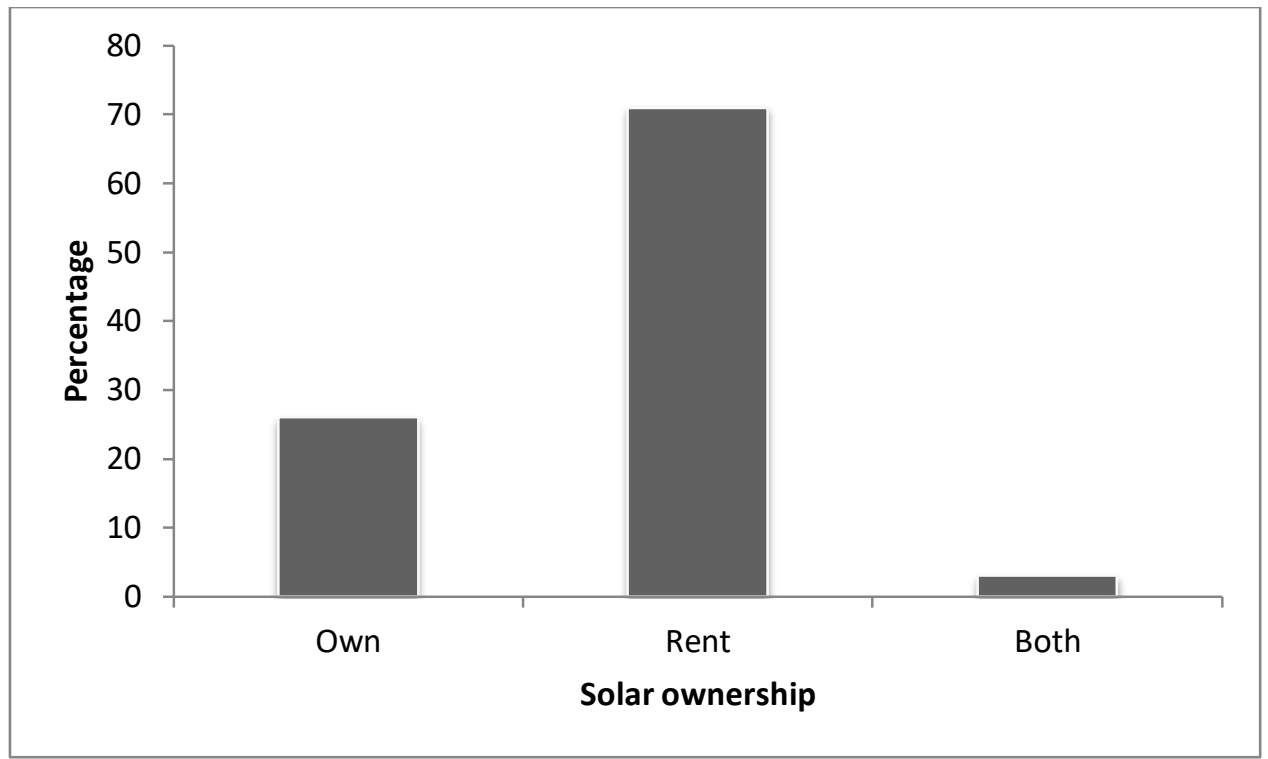

Fig. 4 Solar product ownership

Of the 23 per cent who own solar products, all have solar home systems. Ikisaya Energy Centre is the biggest source of solar products with 80 per cent of the respondents indicating they got their solar product from the centre (Fig. 5). There is very low supply of solar by the local trading centres standing at only 2 per cent.

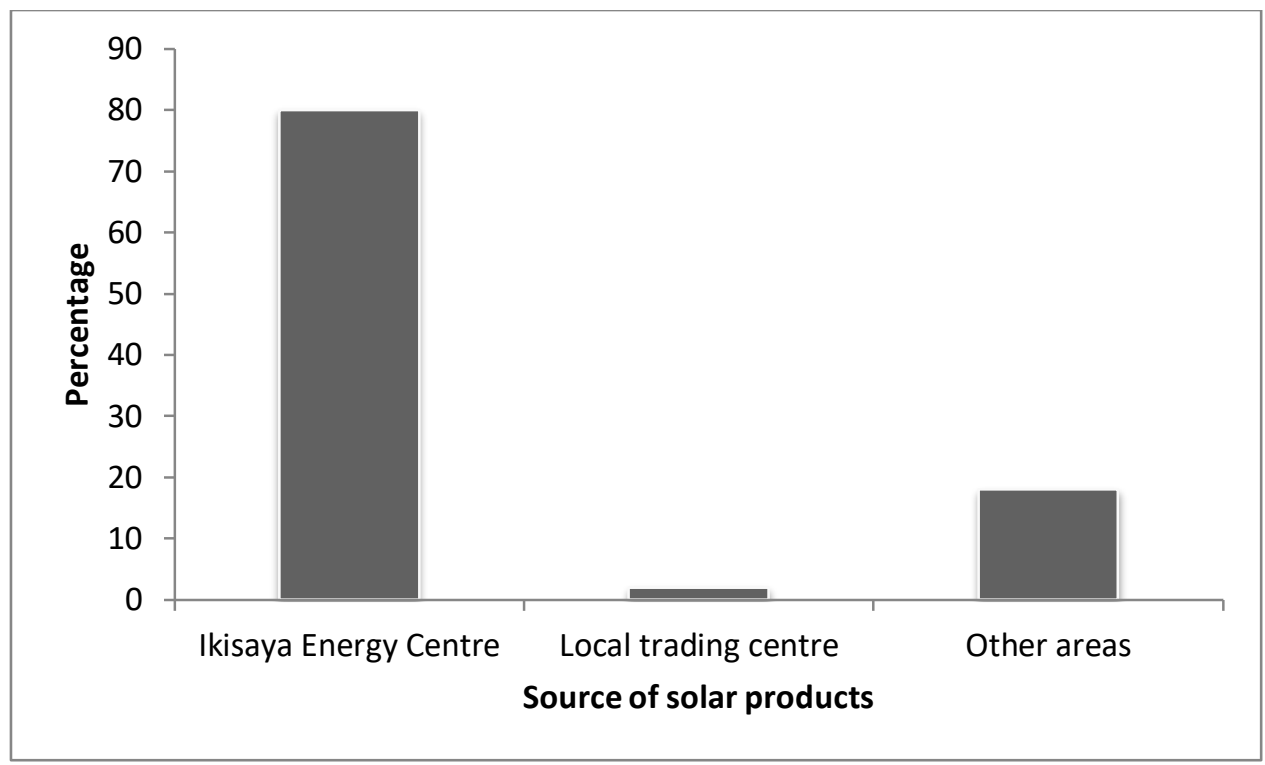

Fig. 5 Source of solar products 


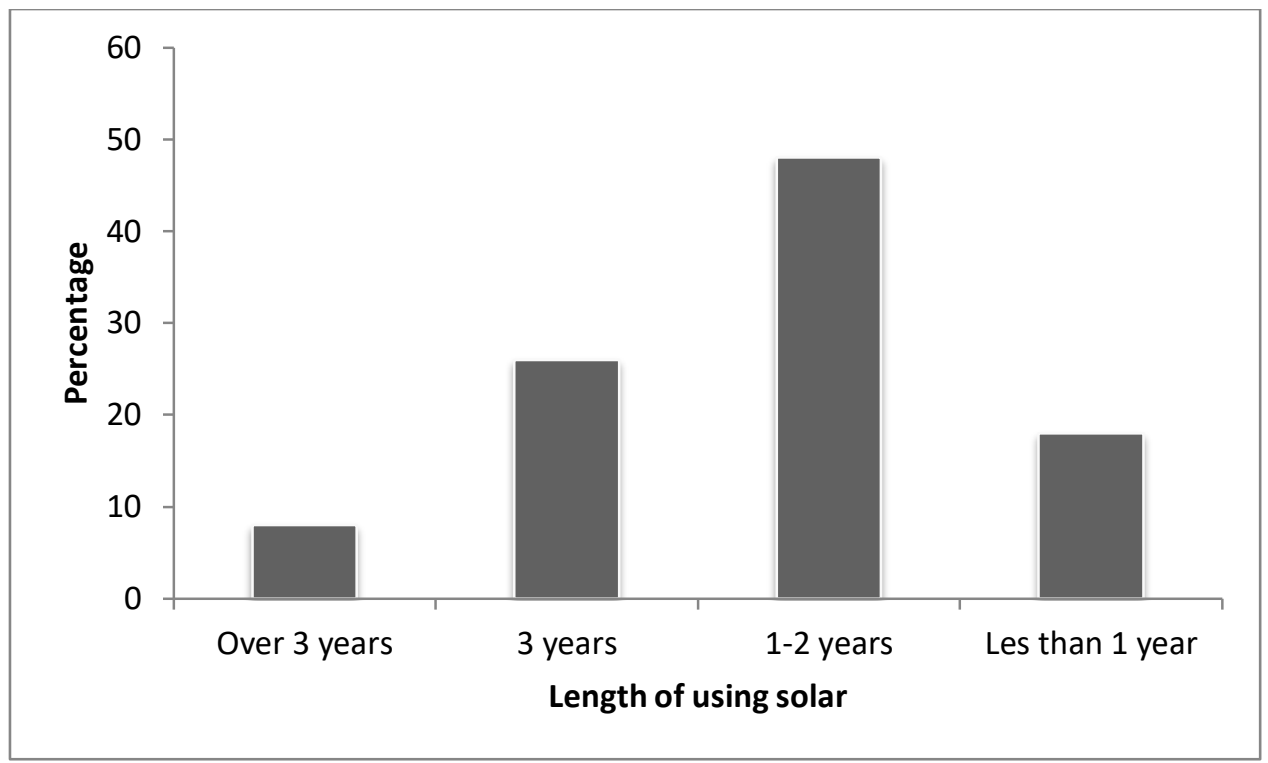

Fig 6 Length of using solar products (years)

Majority of the household interviewed have acquired solar in the last three years (Fig. 6), accounting for 74 per cent of the population. About 91 per cent of the household with solar use the products between 3 times a week or daily (Fig. 7).

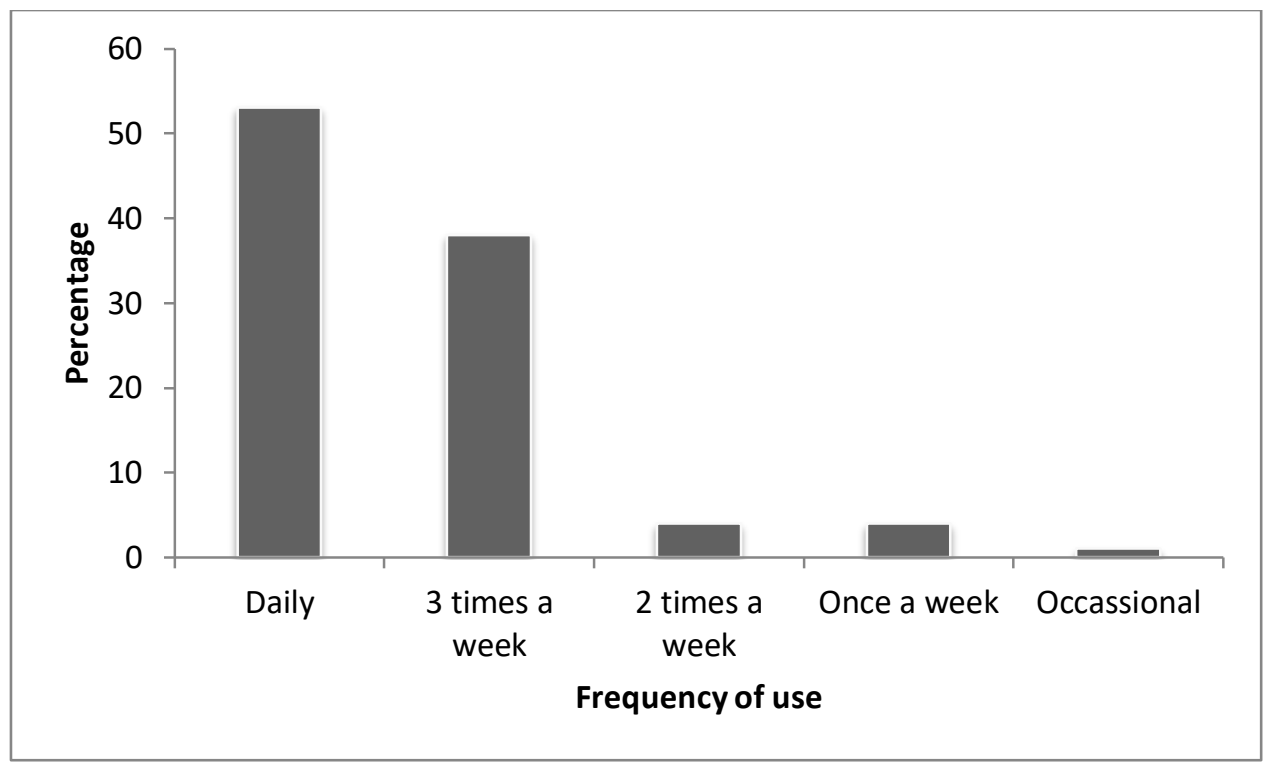

Fig. 7 Frequency of use

Of those who are using solar, 92 per cent want to continue using while 8 per cent do not want to continue using while the rest 8 per cent who want to discontinue using solar is mainly because of the inconvenience in dropping the lanterns at the centre for charging and picking back (Fig. 8). 


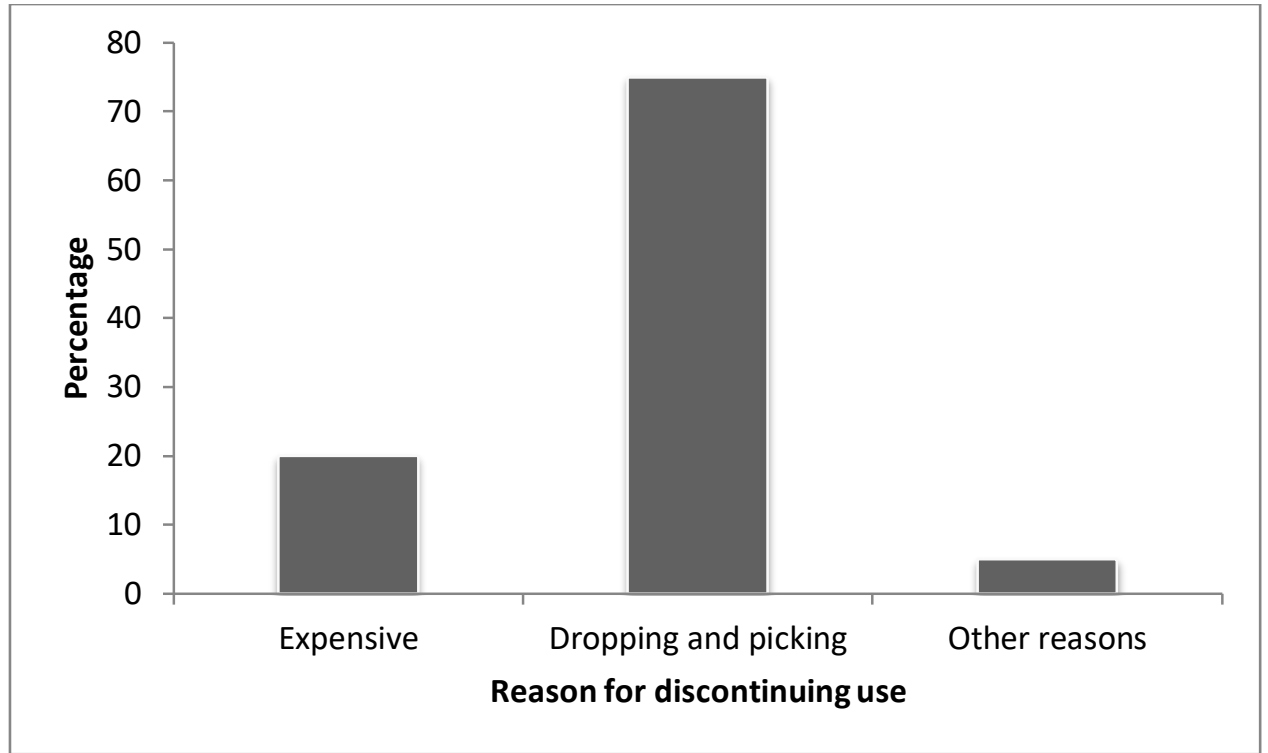

Fig. 8 Reasons to discontinue using solar products

The inconvenience of dropping and picking the lanterns at the energy centre was recorded as the single biggest cause of households discontinuing the use of solar lantern accounting for about 70 per cent of the number of households who discontinued using solar lanterns. Cost was mentioned but not as a major factor contributing to about 20 per cent of the household who dropped the use of solar.

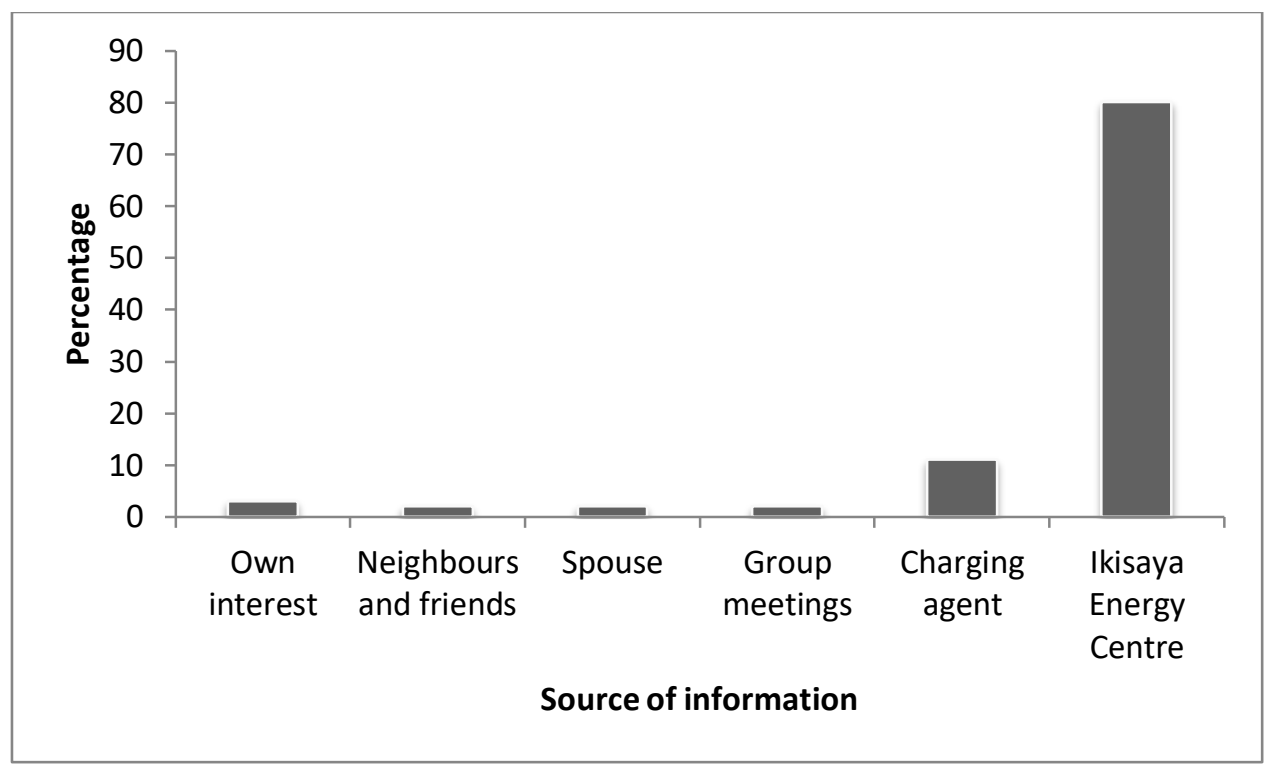

Fig. 9 Source of information on solar products

Majority of information on solar products was received from the Energy Centre accounting for close to 80 per cent of the respondents (Fig. 9). 


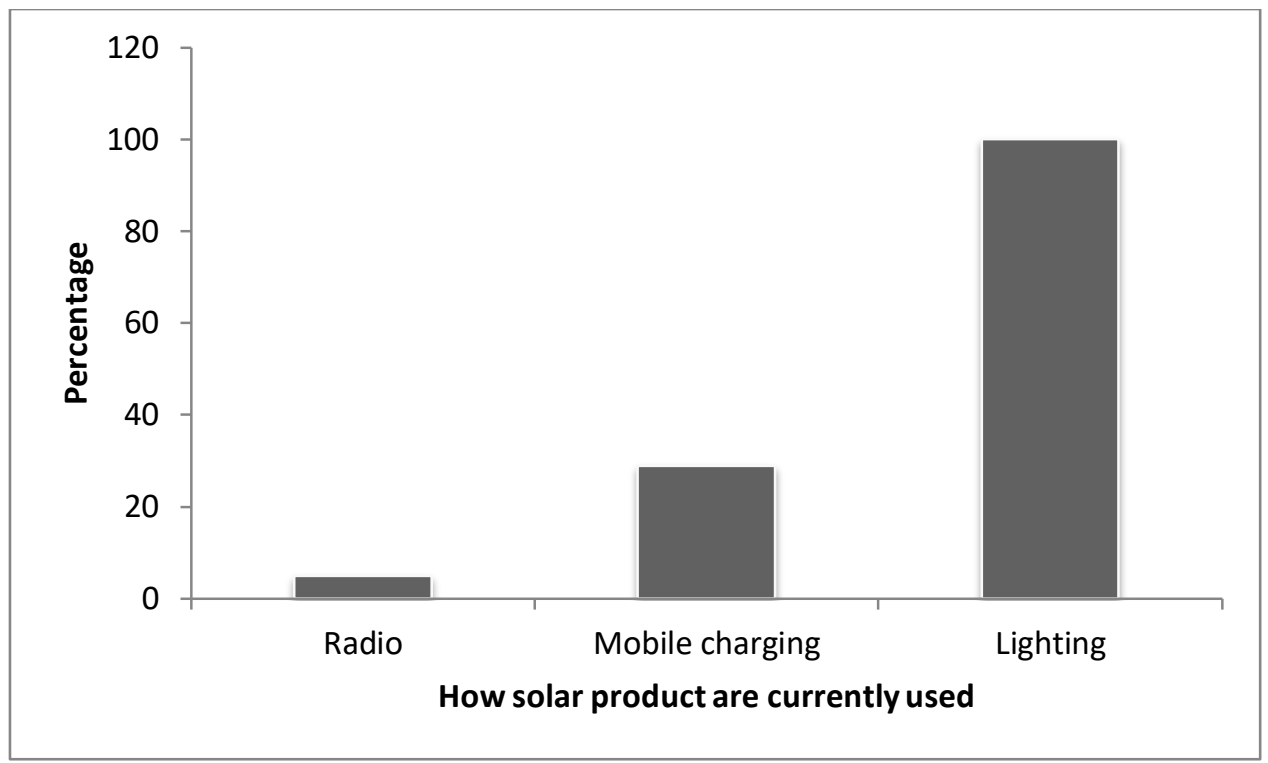

Fig. 10 Current energy services offered by solar products

Lighting and mobile phone charging is leading in the services provided by the current solar products. All respondents indicated lighting while mobile charging was recorded from 30 per cent of the respondents (Fig. 10).

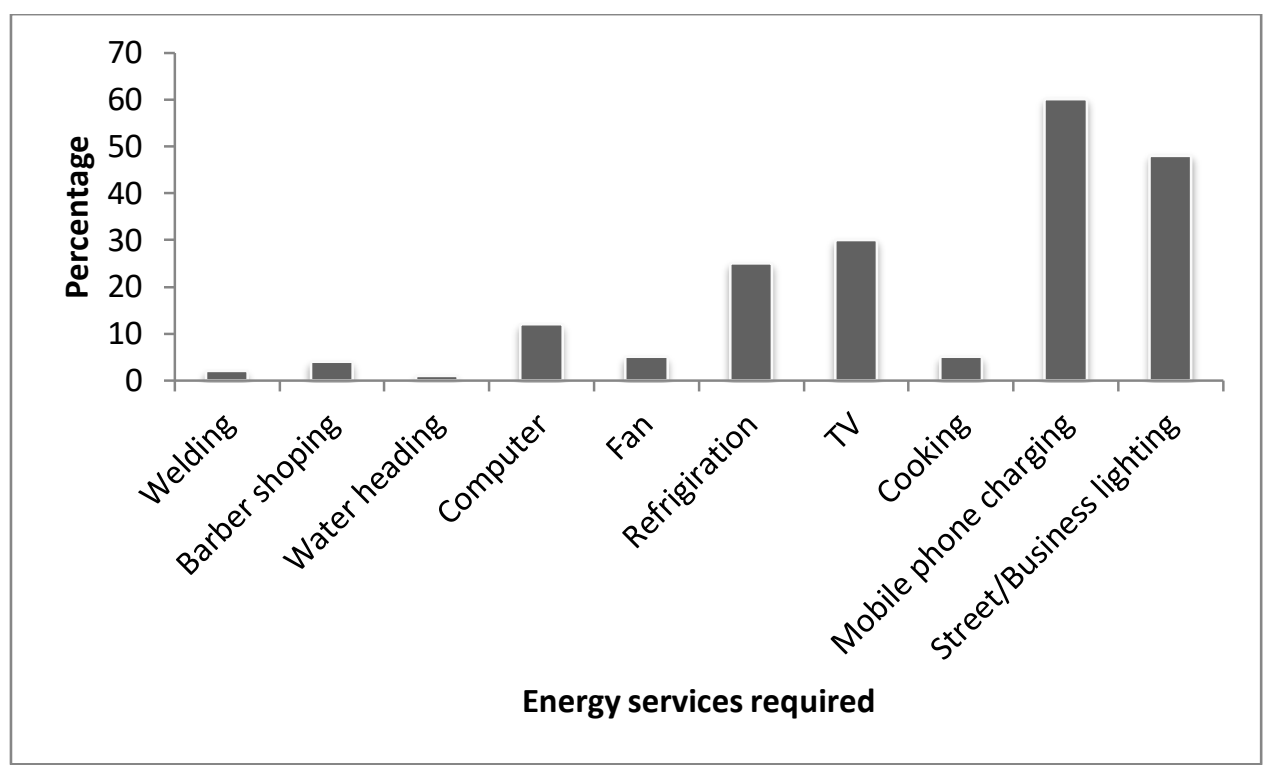

Fig. 11 Other energy services required but not currently offered

In addition to mobile charging services and lighting which scored highly (Fig. 11), other services required include power for television and refrigeration services. 


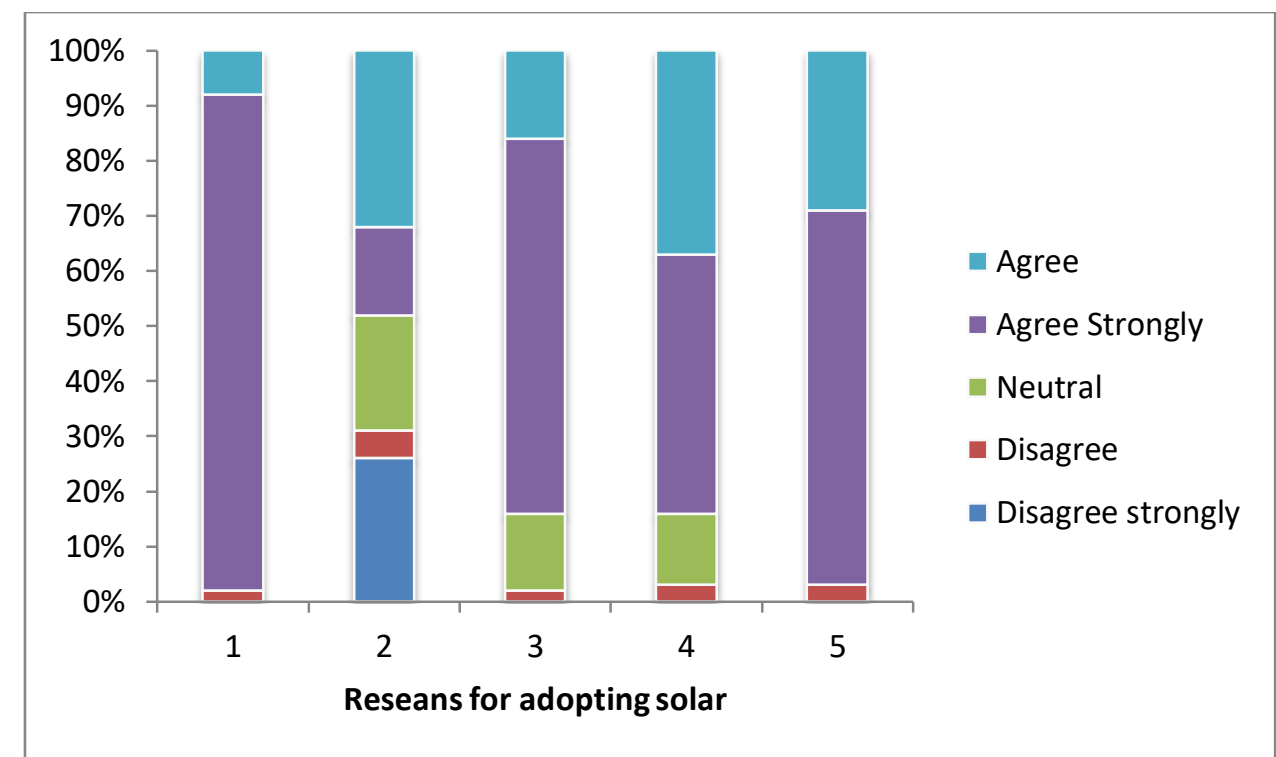

Key: 1. Use of solar gives better lighting than kerosene 2. Use of solar does not meet my energy requirement 3. Use of solar is cheaper in the long run 4. Having solar is a status symbol 5. People important to me expect me to use solar

Fig. 12 Reasons for adopting solar

When respondents were asked the reason for adopting solar, the largest majority (98 per cent) indicated that solar gives better lighting those kerosene lanterns and influence from people important to them. About 90 per cent adopted solar because they believe that solar is cheaper in the long run with equal percentage indicating that solar give them status symbol in the society as the main reason for adoption. It is worthy noting that 30 per cent of the respondents indicated that solar products do not meet their energy requirements.

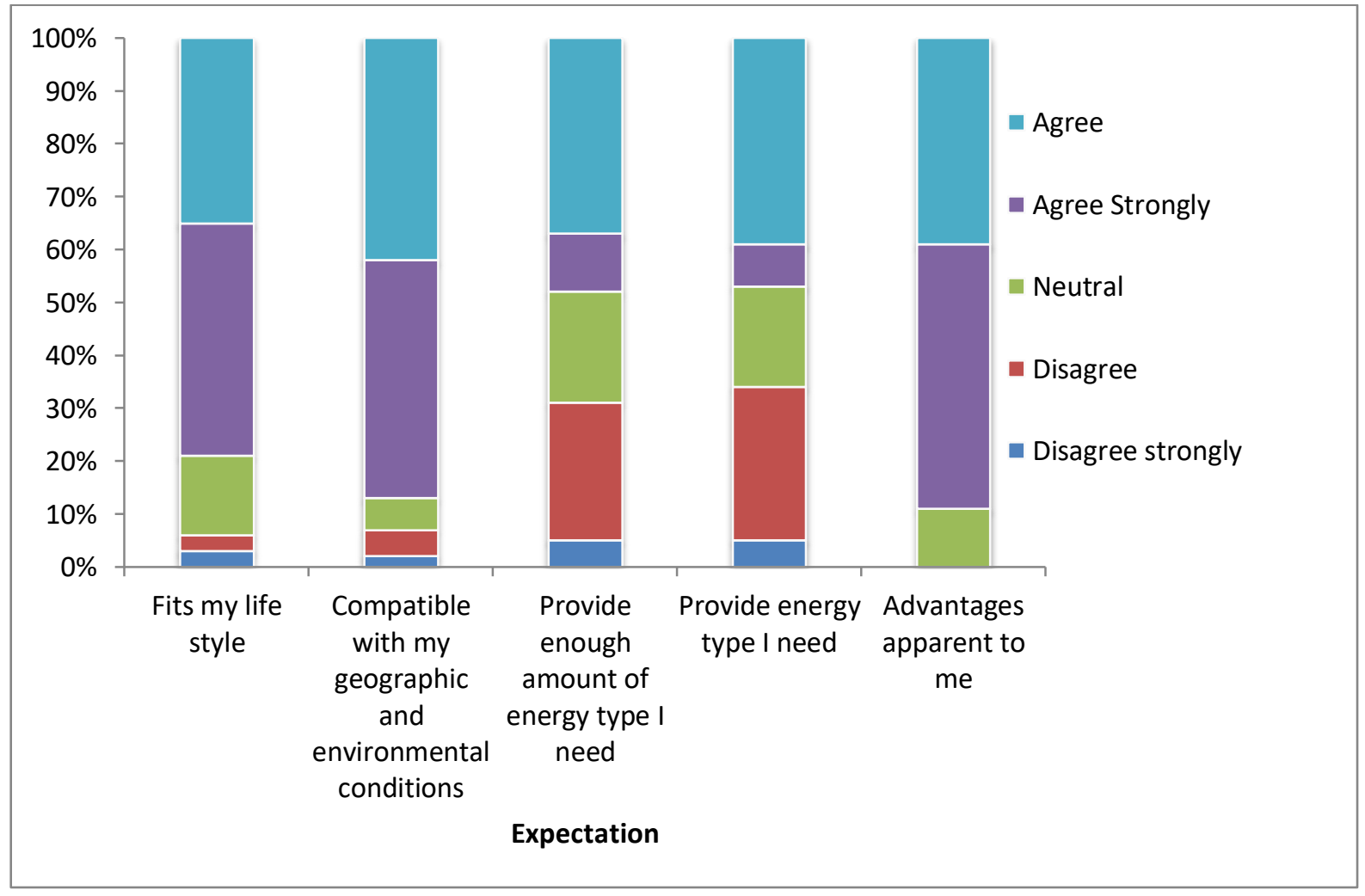

Fig. 13 Meeting energy expectation 
There were generally positive comments about solar with 90 per cent indicating that the advantages of solar were clear to them and compatible with their geographical location, respective. About 30 per cent and 25 per cent of the respondents indicated solar does not provide energy type they expected and that the amount of energy is not enough for their requirements, respectively.

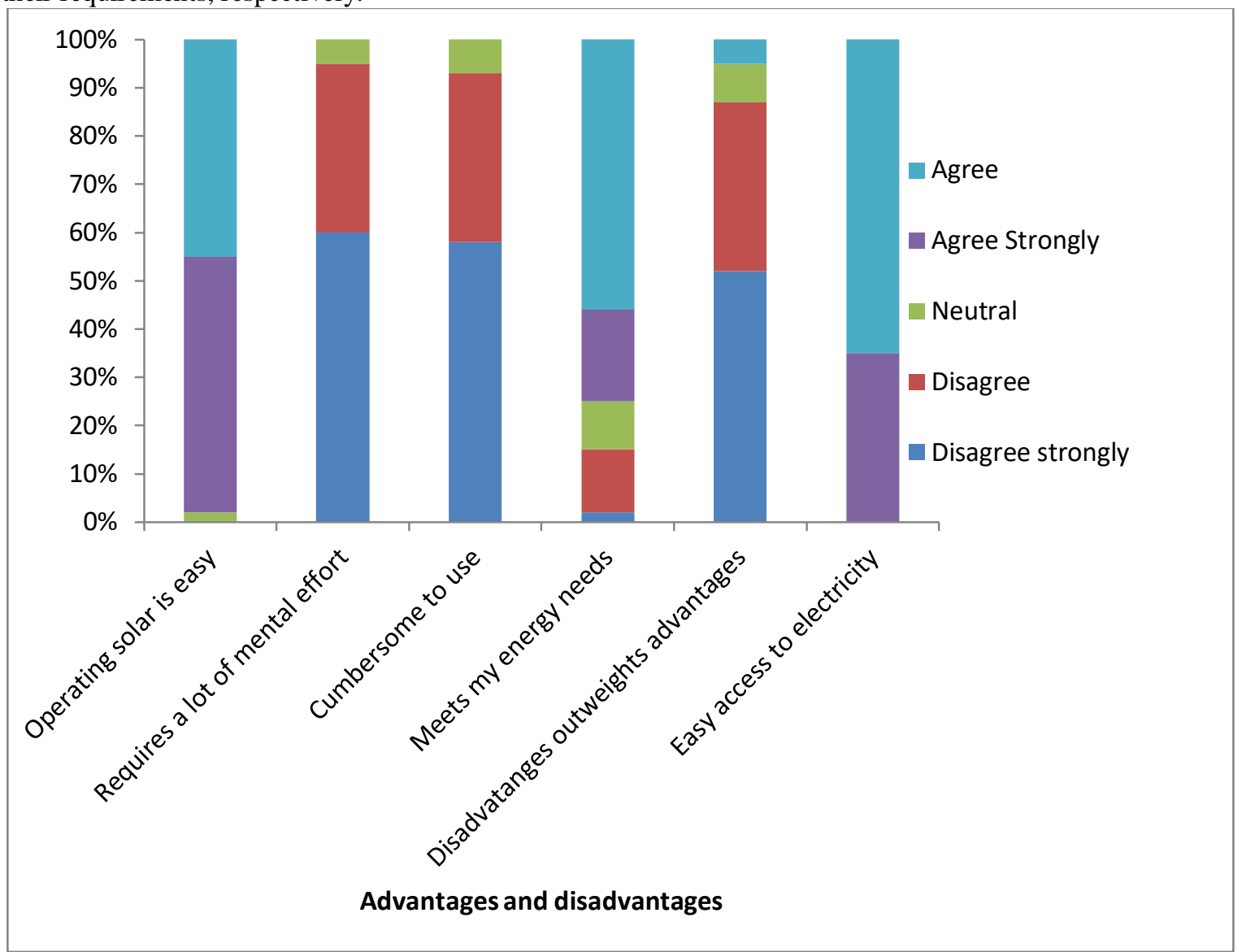

Fig. 14 Advantages and disadvantages of solar

The main advantages of solar were identified as easy access and ease of operation scoring 100 per cent and 95 per cent, respectively while the main disadvantage is that it does not meet the energy requirement of most household (20 per cent) (Fig. 14).

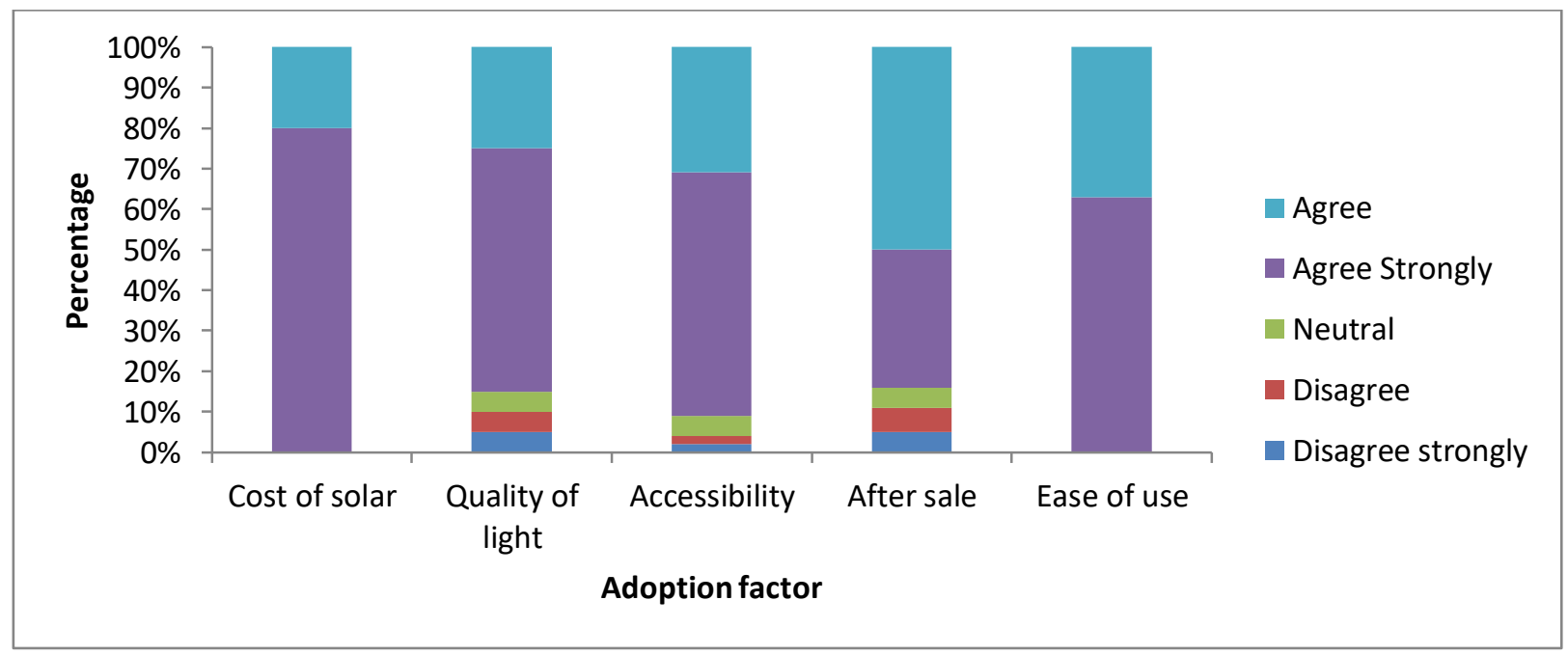

Fig. 15 Adoption factors 
When a question was asked about the factors favouring adoption or otherwise of solar product, all respondents scored ease of use and product cost as the main factor determining adoption of solar products (Fig 15). The other factors such as accessibility, quality of light and after sales services was equally important.

\section{Discussion}

With low literacy level and predominantly farming community, it is no wonder that the majority of the population was predominantly using kerosene candle as a source of lighting prior to the establishment of the Ikisaya Energy Centre. The energy centre has had a huge impact in introducing solar products in the community. This is evident by the fact that over 70 per cent are using rented solar lanterns mainly from the energy centre and over 80 per cent started using solar for the past 3 year which coincides with the establishment of Ikisaya Energy Centre. It is also important to note that a big majority of the community received information about solar products from the centre. In this sense, the centre has played an important role in community awareness and introduction of alternative energy.

The study has demonstrated a positive and high reception of the technology by the community with over 90 per cent indicating thy would wish to continue using the technology with only 8 per cent indicating they wanted to discontinue using the technology. Though this is a small percentage compared to those who are happy, the underlying reason given for discontinuation cast a big question on the suitability of the energy centre model for different households. The reason given is the inconvenience of dropping the lantern for charging in the morning and picking them back in the evening, which the consumers indicated, is a disruption to their daily routine. In the currently study, the centre was purposely established near a school with an assumption that the household would use their children going to school in the morning to drop the lanterns for charging and pick them back on their way home. While this sounds a good thinking, the model did not consider households without school going children. This may call for a consideration of a mixed model to provide stand alone systems for households who find central charging centre not suitable to their lifestyle.

It was a general opinion that the centre offers two basic but very important services, lighting and mobile phone charging, which is at the top of energy needs of the community. This notwithstanding, there is a general feeling that the energy provided is not enough in an area where there is no grid electricity in the vicinity. The respondents felt there is a need to introduce energy for productive use such as refrigeration especially for the small businesses and health centres.

The study revealed a number of underlying issues that affect adoption and use of solar by the community. A number of reasons were given which influence adoption of solar products. Chief a mong these was the belief that solar products are cheaper in the long run and they give better light than kerosene candles. Influence by opinion shapers also played an important role in influencing households to adopt solar products. Surprisingly a high percentage indicated that having solar gave them some status symbol in the society and this influenced their decision to adopt solar.

The study identified among the key factors for adoption as price of the product, ease of operation, accessibility and quality of light. Also score in this category though not as highly is availability of after sales. After sales services is a big factor in adoption [2]. The reason it may be appearing low in the presence case could be due to the fact that in the energy centre model, the centre management takes care of maintenance so the consumers may not notice this as a factor.

Though the disadvantages of solar did not future prominently in the current study, some of the main worries on the use of solar identified by the respondents include incompatibility with the lifestyle, this was especially so for those household without school going children to drop and pick the lanterns from the centre. Other factors include the fact that solar does not provide total energy needs of the household and to lesser extent technical operational issues, especially in a community with low literacy levels.

Discussion with focused groups revealed that centre governance remains a major challenge. A community group manages the centre while day-to-day employees paid from the revenue collected on lanterns and mobile phones charging. Ideally the revenue was meant to pay the workers and a percentage kept to finance any maintenance and changing worn out batteries. This objective is yet to be achieved and the project donors are forced to subsidize to replace worn out batteries.

\section{Conclusion}

The energy centre has played a major role in introducing solar technology to a community predominantly using kerosene candles for lighting. The technology has been well received and most households are willing to pay for continued use. 
Thought the model is providing access to clean energy, there are fundamental issues that need to be addressed. These include long term sustainability, robustness of the model to cater for households who for one reason or the other find it difficult to drop and pick lanterns at the centre on daily basis. Centre governance is an issue of sustainability that need to be addressed.

\section{Acknowledgements}

The author wish to thank Dr. Kirsten Ulsrud of the University of Oslo, the project leader, Debajit Palit of the Energy Resource Institute (TERI), African Centre for Technology Studies staff who were involved in the study. Finally the author wants to recognize the contribution of the Ikisaya Energy Centre staff and all the respondents who provided valuable information.

\section{Reference}

1. World Energy Outlook 2014 report. IEA, Paris. 2014.

2. Muok, B.O. and Makokha, W.B. Accelerating Energy Access to the Rural Poor in Kenya through Pico-Solar Market Development. International Journal of New Technology and Research (IJNTR), Volume-3, Issue-10, October 2017 Pages 37-44.

3. Green economy report. UNEP, Nairobi, 2014.

4. http://www.erc.go.ke/index.php?option=com_fsf \&view=faq\&catid=2\&Itemid $=649$

5. Hankins M., A. Saini, and P. Kirai. Target market analysis. Kenya's solar energy market 2009. Available

at <https://www.giz.de/fachexpertise/downloads/gt z2009-en-targetmarketanalysis-solar-kenya.pdf>, last accessed on October 3, 2017. 